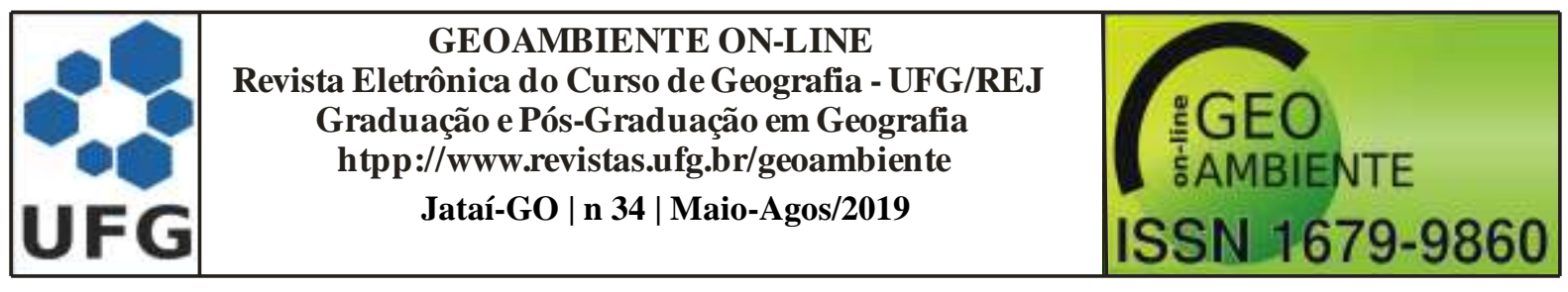

\title{
GERENCIAMENTO DA ÁGUA E O IMPACTO NA SAÚDE DA POPULAÇÃO DO BAIRRO SANTA MARGARIDA, MUNICÍPIO DE SALGUEIRO (PE)
}

\author{
Ádilla Katarinne Gonçalves e Sá ${ }^{1}$, Eduardo José Alécio de Oliveira ${ }^{2}$, Ronaldo Faustino da \\ Silva $^{3}$, Sofia Suely Ferreira Brandão Rodrigues ${ }^{4}$
}

(1 - Faculdade de Ciências Humanas do Sertão Central - FACHUSC, Professora Universitária do Curso de Ciências Biológicas, adillakgs@hotmail.com, 2 - Instituto Federal de Pernambuco - IFPE, Professor do Programa de Pós-graduação em Mestrado Profissional em Gestão Ambiental, edualecifpe@gmail.com, 3 - Instituto Federal de Pernambuco - IFPE, Professor do Programa de Pós-graduação em Mestrado Profissional em Gestão Ambiental, ronaldofaus@gmail.com, 4 - Instituto Federal de Pernambuco - IFPE, Professora do Programa de Pós-graduação em Mestrado Profissional em Gestão Ambiental, sofiabrandaorodrigues@gmail.com)

Resumo: O presente artigo busca compreender as doenças de veiculação hídrica, no Bairro Santa Margarida, localizado no município de Salgueiro - PE, identificando o tipo de acesso, o armazenamento e a qualidade da água potável. Para isto, foram solicitados da vigilância epidemiológica do município, dados referentes ao quantitativo de casos confirmados das principais doenças, no período de 2015 a 2017 e aplicado um questionário semiestruturado em 66 residências. Os resultados revelaram que a maioria da população possui água encanada nas residências, porém com uma duração média de 3 dias por semana, o que os obriga a armazenar água, muitas vezes em recipientes não adequados e nem sempre tampados e limpos com frequência, contribuindo para a proliferação de doenças. Por considerarem a água que chega às torneiras de boa qualidade, muitos acabam consumindo ou higienizando os alimentos da forma como a mesma lhe é fornecida, colocando em risco a saúde pública local. Dentre as doenças mais comuns, estão diarreia e dengue o que torna necessária a efetivação das

\footnotetext{
Artigo recebido para publicação em 27 de Maio de 2019

Artigo aprovado para publicação em 26 de Agosto de 2019
} 


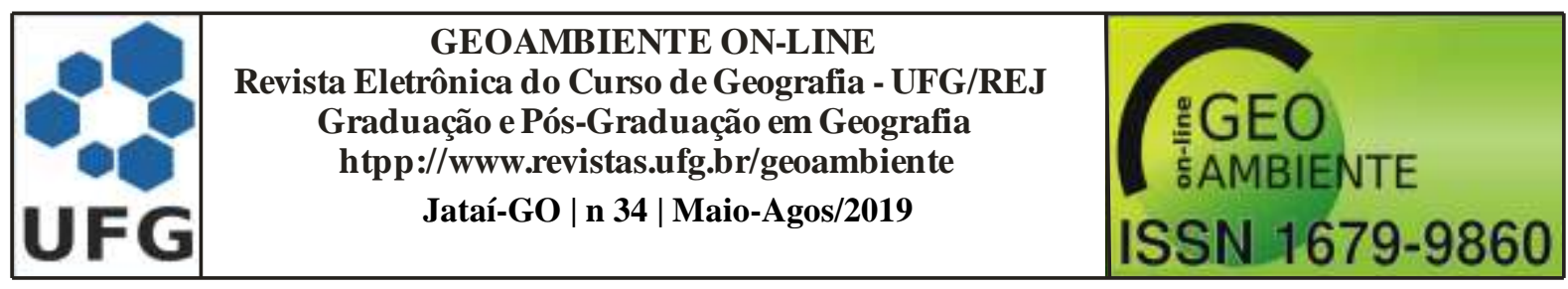

campanhas educativas e de políticas públicas que possam garantir à população o direito de acesso total ao saneamento básico adequado.

Palavras-chave: Saúde pública, armazenamento de água, doenças de veiculação hídrica.

\section{WATER MANAGEMENT AND THE IMPACT ON THE HEALTH OF THE POPULATION OF BAIRRO SANTA MARGARIDA, CITY OF WILLOW (PE)}

Abstract: This article aims to understand the waterborne diseases in the Santa Margarida neighborhood, located in the city of Salgueiro - PE, identifying the type of access, storage and quality of drinking water. For this purpose, data on the number of confirmed cases of the main diseases were requested from the epidemiological surveillance of the municipality, from 2015 to 2017, and a semistructured questionnaire was applied to 66 residences. The results showed that most of the population has piped water in their homes, but with an average duration of 3 days a week, which forces them to store water, often in unsuitable containers and not always capped and cleaned frequently, contributing to the proliferation of diseases. By considering the water that reaches the taps of good quality, many end up consuming or sanitizing the food in the way it is supplied, putting the local public health at risk. Among the most common diseases are diarrhea and dengue, which makes it necessary to carry out educational campaigns and public policies that can guarantee the population the right to full access to adequate basic sanitation.

Key-words: Public health, water storage, waterborne diseases.

\section{MANEJO DEL AGUA Y EL IMPACTO EN LA SALUD DE LA POBLACIÓN DE BAIRRO SANTA MARGARIDA, CIUDAD DE SALGUEIRO (PE)}

Resumen: Este documento tiene como objetivo comprender las enfermedades transmitidas por el agua, en el barrio de Santa Margarida, ubicado en Salgueiro - PE, identificando el tipo de acceso, almacenamiento y calidad del agua potable. Para ello, se solicitó la vigilancia epidemiológica del municipio, datos sobre el número de casos confirmados de enfermedades graves, de 2015 a 2017 y se aplicó un cuestionario semiestructurado en 66 hogares. Los resultados revelaron que la mayoría de la población tiene agua corriente en los hogares, pero 


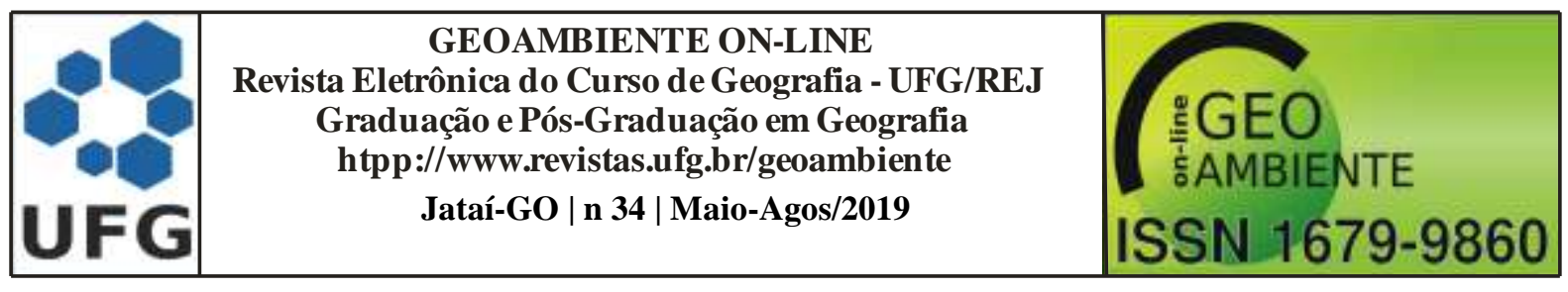

con una duración promedio de 3 días por semana, lo que los obliga a almacenar agua, a menudo en contenedores inadecuados y no siempre tapados y limpiados con frecuencia, lo que contribuye a La proliferación de enfermedades. Considerando el agua que llega a los grifos de buena calidad, muchos terminan consumiendo o desinfectando alimentos a medida que se suministran, poniendo en peligro la salud pública local. Entre las enfermedades más comunes se encuentran la diarrea y el dengue, lo que hace necesario llevar a cabo campañas educativas y políticas públicas que puedan garantizar a la población el derecho al pleno acceso a un saneamiento adecuado.

Palabras clave: Salud pública, almacenamiento de agua, enfermedades transmitidas por el agua.

\section{Introdução}

A água é um elemento essencial para a sobrevivência de vida no planeta Terra. O gerenciamento adequado da água potável, tanto em quantidade como em qualidade, é primordial para o desenvolvimento socioeconômico, já que reflete diretamente nas condições de saúde e de bem-estar da população.

Segundo Razolini (2008) as condições adequadas de abastecimento e saneamento de uma comunidade resultam na melhoria da qualidade de vida, pois possibilita o controle e a prevenção de doenças e a prática diária de hábitos higiênicos, aumentando a expectativa de vida e a produtividade econômica local.

Uma das primeiras relações entre a água e a proliferação de doenças surgiu a partir das indicações de Pauster, por volta de 1860, ao constatar que várias doenças poderiam ser causadas por microrganismos. Além dele, John Snow, em 1885, analisou a epidemia de cólera em Londres, demonstrando que a transmissão da doença ocorria através da água. Estabelecendo assim, as relações entre o social e o seu processo de transmissão na população (BRANCO et al., 2006; JUNQUEIRA, 2009; ROUQUAYROL et al., 2013).

De acordo com Amaral et al. (2003) as doenças de veiculação hídrica são causadas principalmente por meio de microrganismos patogênicos que têm suas origens relacionadas aos fatores espaciais do território e são determinadas pelos preceitos capitalistas e dicotômicos que regem a sociedade, assumindo relevância, entre outros aspectos, na 


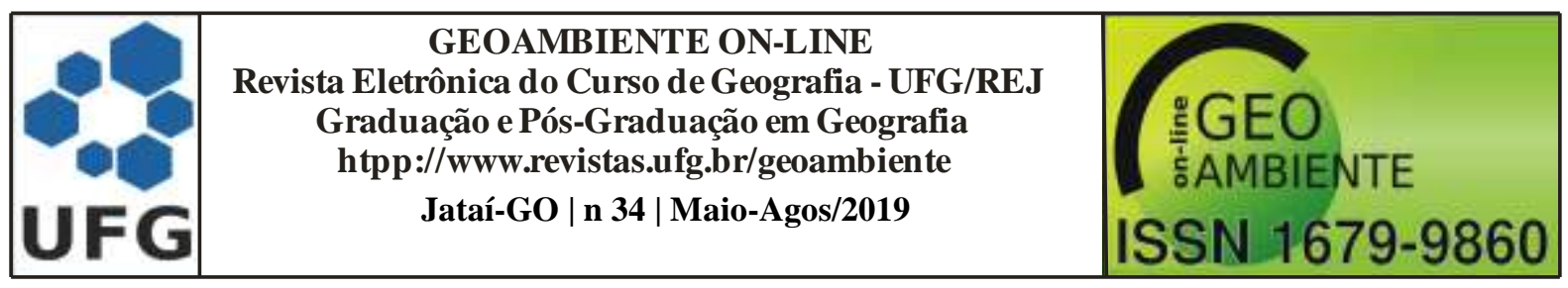

determinação de desigualdades no que tange a qualidade da água para consumo e uso humano. Ou seja, a captação de água em localidades sem os recursos necessários, expostos a várias fontes de contaminação, aumenta consideravelmente o risco a determinados agravos ou surtos de doenças nestas localidades.

Partindo desses pressupostos, Nere (2010) enfatiza que para o desenvolvimento de sistemas de água com suficiente qualidade necessita de outros sistemas mais amplos que considerem a necessária melhoria dos aparelhos de saneamento básico como um todo. Dessa forma, um município que não possui abastecimento de água por meio de recursos hídricos, em suas especificidades de qualidade através do tratamento e quantidade armazenada corretamente, apresenta maior vulnerabilidade ao risco de doenças.

Dados da Organização Mundial de Saúde - OMS (BRASIL, 2015) mostra que desde 2010, a água de qualidade inadequada e a falta de saneamento e higiene causam aproximadamente $3,1 \%$ de todos os óbitos, isso significa a morte de aproximadamente 1,7 milhão de pessoas em todo mundo. Ademais, 3,7\% dos anos de vida perdidos por problemas de saúde podem ser atribuídos às doenças mais impactantes transmitidas pela água. Dentre as principais patologias associadas à água estão a diarreia, a cólera, a esquistossomose, a leptospirose, a hepatite A e as epidemias da dengue (BRASIL, 2016).

Este artigo tem como objetivo compreender as doenças ocasionadas pela água, no Bairro Santa Margarida, localizado no município de Salgueiro - PE, no período de 2015 a 2017, identificando o tipo de acesso, o armazenamento e a qualidade desta água. Além de estabelecer possíveis relações desses aspectos com frequência dessas doenças. Este bairro é um dos mais populosos da cidade e apresenta uma média de renda familiar per capita de até um salário mínimo.

\section{Materiais e Métodos}

\subsection{Caracterização da Área de Estudo}

O município de Salgueiro está localizado no Sertão de Pernambuco, no cruzamento das rodovias federais 232 e 116 (Figura 1). Segundo o Instituto Brasileiro de Geografia e Estatística (IBGE, 2016) possui uma população estimada de 60.117 habitantes, distante a 518 km da capital Recife; sua área territorial é de 1686,815 km² e densidade demográfica de 33,57 


\begin{tabular}{|c|c|c|}
\hline & $\begin{array}{c}\text { GEOAMBIENTE ON-LINE } \\
\text { Revista Eletrônica do Curso de Geografia - UFG/REJ } \\
\text { Graduação e Pós-Graduação em Geografia } \\
\text { htpp://www.revistas.ufg.br/geoambiente } \\
\text { Jataí-GO | n 34 | Maio-Agos/2019 }\end{array}$ & $\begin{array}{c}\text { GEO } \\
\text { G G }\end{array}$ \\
\hline
\end{tabular}

hab. $/ \mathrm{km}^{2}$, possui esgotamento sanitário adequado, beneficiando $62,8 \%$ dos domicílios. Por possuir clima semiárido, com temperatura média anual de $25^{\circ} \mathrm{C}$, apresenta chuvas escassas e mal distribuídas, vegetação xerófila e rios temporários. Sua precipitação volumétrica varia de 450 a $600 \mathrm{~mm} / \mathrm{ano}$ e os meses chuvosos são de dezembro a março (PREFEITURA DE SALGUEIRO, 2017). A pesquisa foi desenvolvida no bairro Santa Margarida que, conforme informações colhidas na vigilância sanitária epidemiológica do município, possui 57 quarteirões com total de 2.292 imóveis, dos quais 1.997 são residências.

Figura 1 - Mapa territorial do município de Salgueiro - PE.

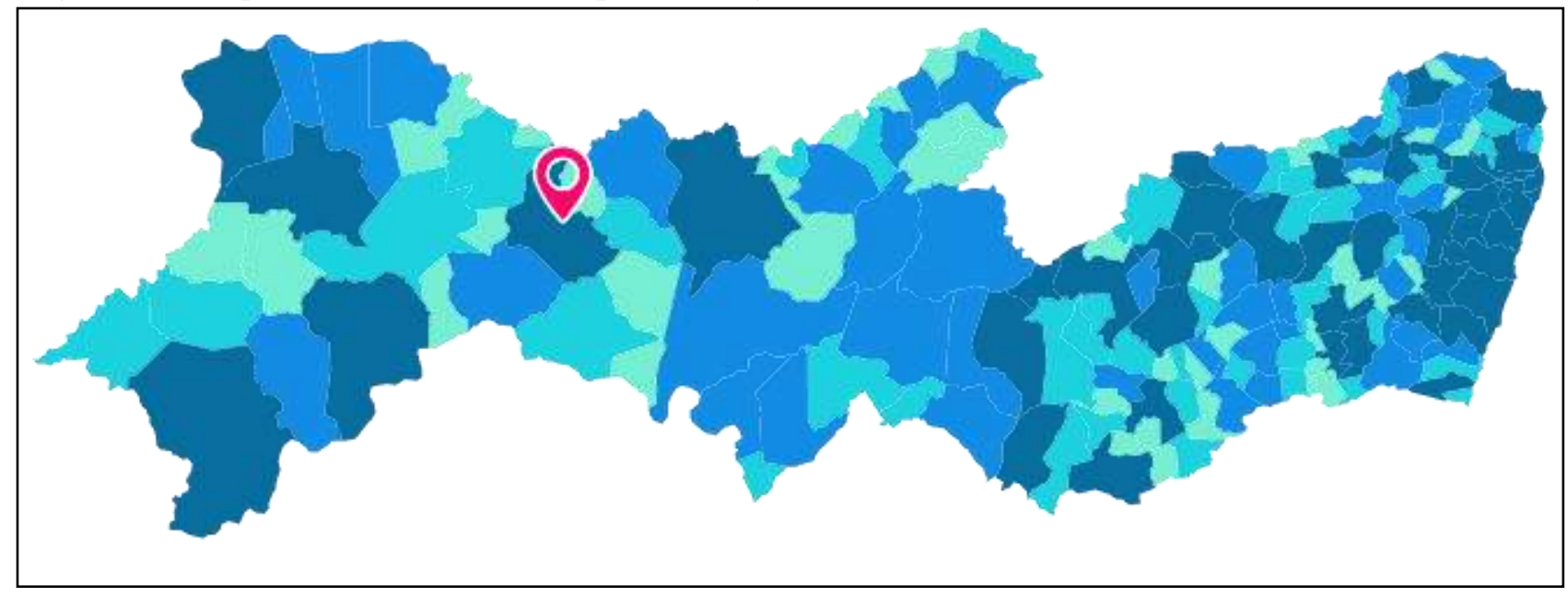

Fonte: IBGE, 2016.

\subsection{Coleta e Tabulação dos Dados}

Foram solicitados da vigilância epidemiológica do município, dados referentes ao quantitativo de casos confirmados, no bairro pesquisado, de epidemias da dengue, hepatite tipo A, cólera, esquistossomose, diarreia e leptospirose, dos anos de 2015, 2016 e 2017, que conforme o Ministério da Saúde (BRASIL, 2016), são as doenças de vinculação hídrica mais comum no país. Além desses dados, aplicou-se no período de dezembro de 2016 e janeiro de 2017, um questionário semiestruturado em 66 residências, escolhidas de forma aleatória, para identificar a presença ou não de água encanada nas residências, sua duração e a percepção da qualidade por parte dos moradores, a forma de conservação, consumo e armazenamento da água potável e a maneira de higienização dos alimentos no bairro. Esses dados foram 


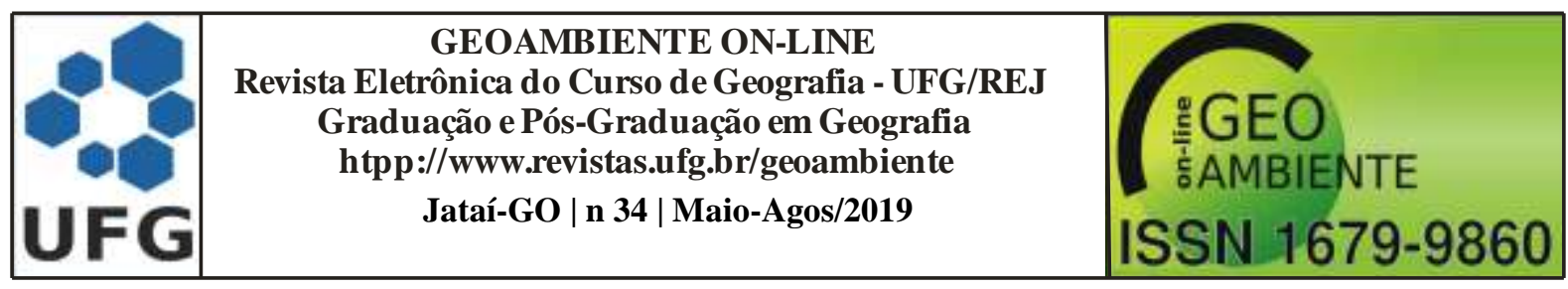

tabulados pelo programa Excel do software da Microsoft e os resultados apresentados na forma de gráficos do tipo colunas.

Para o cálculo de determinação da amostra, utilizou-se o método de Oliveira et al (2004), uma vez que a população é inferior a cem mil habitantes, de acordo com a seguinte fórmula:

$$
n=\frac{s^{2} \cdot p \cdot q \cdot N}{e^{2}(N-1)+S^{2} p \cdot q}
$$

Onde:

$\mathrm{n}=$ tamanho da amostra.

$\mathrm{S}=$ nível de confiança escolhido, expresso em número de desvios-padrão $=90 \%$ que conforme o valor tabelado aproximado pela distribuição nominal é de 1,65.

$\mathrm{p}=$ percentagem com a qual o fenômeno se verifica - percentagem dos elementos da amostra favorável ao atributo pesquisado.

$\mathrm{q}=$ percentagem complementar, isto é, $(100-\mathrm{p})$ - percentagem dos elementos da amostra desfavorável.

$$
\begin{aligned}
& \mathrm{N}=\text { tamanho da população. } \\
& \mathrm{e}=\text { erro máximo permitido }=10 \% .
\end{aligned}
$$

\section{Resultados e Discussão}

Silva Filho, Morais e Silva (2013), enfatizam que a manutenção e qualidade da água tanto de sistemas de distribuição, quanto de sistemas naturais são fundamentais para a qualidade de vida populacional mantida por esses recursos e, que alguns dos fatores que podem comprometer essa qualidade e consequentemente da saúde humana, estão associados aos aspectos químicos e biológicos da fonte natural e a eficácia do processo de tratamento e armazenamento. Assim, a percepção dos moradores, em relação a sua importância nesse processo é fundamental para que haja uma melhor forma de armazenamento, conservação e consumo da água potável, para que se obtenham condições eficientes de saúde e bem estar da população local. 


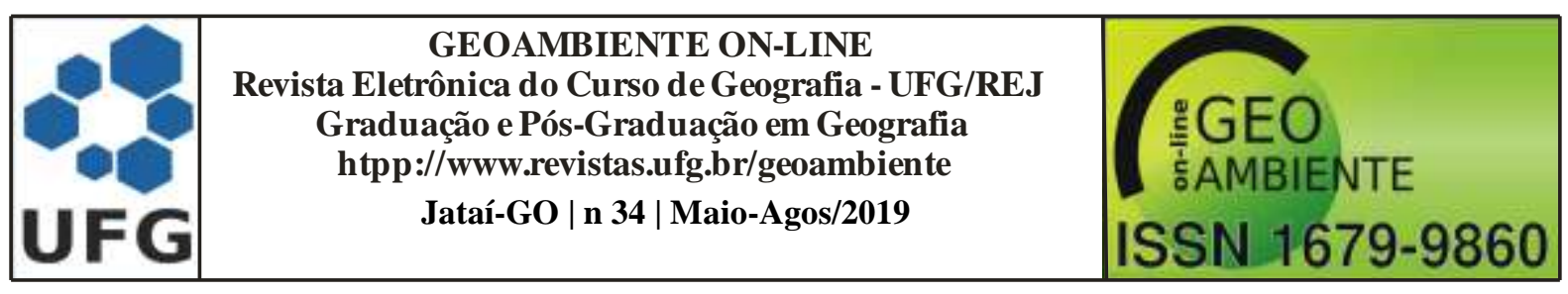

3.1 Percepção dos moradores.

Com base nos questionários, 91\% da população do Bairro Santa Margarida, possuem água encanada, porém a duração desta água, em 58\% das residências é de 1 a 3 dias por semana, sendo de 3 a 5 dias por semana em 26\% delas (Figura 2), o que obriga os moradores a armazenarem água para os demais dias da semana em recipientes muitas vezes inadequados.

Figura 2 - Duração de água encanada na residência, no bairro Santa Margarida, Salgueiro PE.

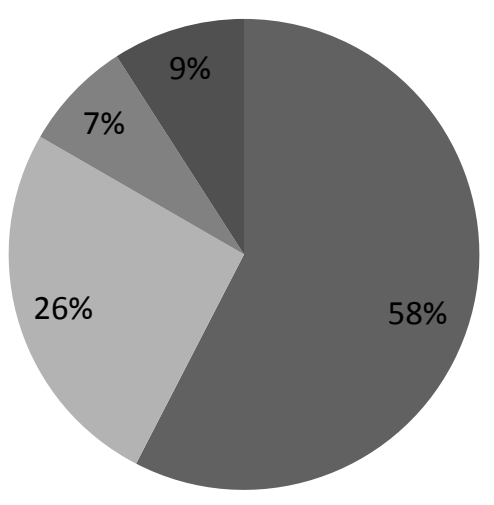

1 a 3 dias da semana

3 a 5 dias da semana

A cada 15 dias

- Não tem água encanada

Fonte: Sá et al., 2018.

O não acesso à água potável e segura ou o acesso de forma intermitente compromete os usos menos imediatos e as condições de higiene, essas situações induzem à busca de água em fontes alternativas, de qualidade sanitária duvidosa, ao uso de vasilhames não apropriados para seu acondicionamento e a condições inadequadas de transporte e armazenamento da água (RAZZOLINI; GÜNTHER, 2008).

A maioria da população do bairro (55\%) armazena a água fornecida pele rede de abastecimento do Estado, em caixa d'água de plástico (Figura 3), sendo esta uma das formas mais corretas de armazenamento, porém outras formas também são usadas como os baldes plásticos (27\%) e as cisternas (7\%). O que mais preocupa é que 9\% destes recipientes não são tampados adequadamente e nem lavados com frequência, o que facilita a contaminação da água por patógenos, a proliferação de mosquitos e a veiculação de doenças relacionadas. 


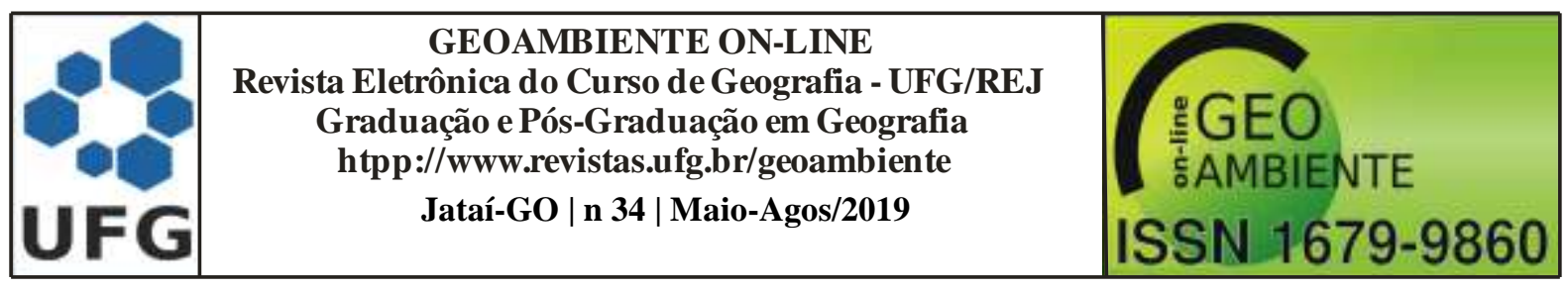

Atualmente, as epidemias da dengue tem sido um dos graves problemas de saúde pública, sendo as caixas d'água um dos principais criadouros do mosquito transmissor. Um estudo feito por Marques et al. (2013), mostrou que fêmeas do Aedes aegypti preferem depositar seus ovos em caixas d'água onde a quantidade de nitrogênio amoniacal está em quantidade elevada, sendo este um importante indicador de poluição, tornando a água não tão potável quanto deveria, logo a limpeza das caixas d'água deveriam ser realizadas em média a cada seis meses.

Figura 3 - Formas de armazenamento de água, pelos moradores do bairro Santa Margarida, Salgueiro - PE.

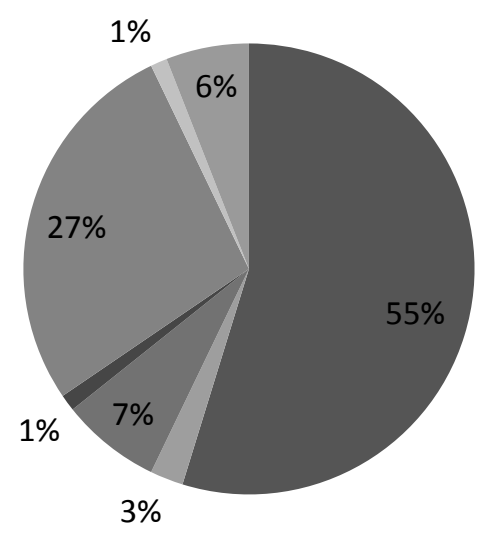

- Caixa d'água de plástico
Caixa d'água de alvenaria
Cisterna
Cacimba
Balde plástico
Lata
Não respondeu

Fonte: Sá et al., 2018.

Com relação à percepção dos moradores do Santa Margarida da qualidade da água encanada, $17 \%$ afirmaram ser ótima e $45 \%$ boa, porém 32\% disseram regular (Figura 4), 21\% desses moradores afirmaram que às vezes, essa água apresentar cor amarelada devido ao excesso de barro que chega junto a água e o cheiro forte de cloro.

Silva, Heller e Carneiro (2012) esclarecem que embora haja o reconhecimento de que se faz necessário o consumo humano da água de qualidade a fim de se evitar doenças, há uma discrepância em relação ao seu acesso. Ainda no que tange a problemática do fornecimento de água, percebe-se que a totalidade dos moradores necessita de outras formas de abastecimento, considerando, sobretudo, a ineficácia quanto à distribuição deste recurso pela empresa responsável por essa distribuição. 


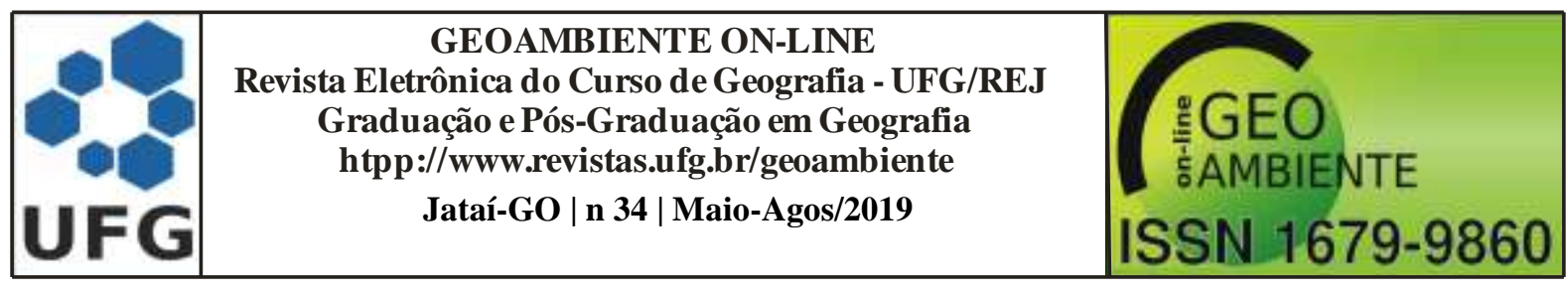

Figura 4 - Percepção da qualidade da água que chega a residência por parte dos moradores do bairro Santa Margarida, Salgueiro - PE.

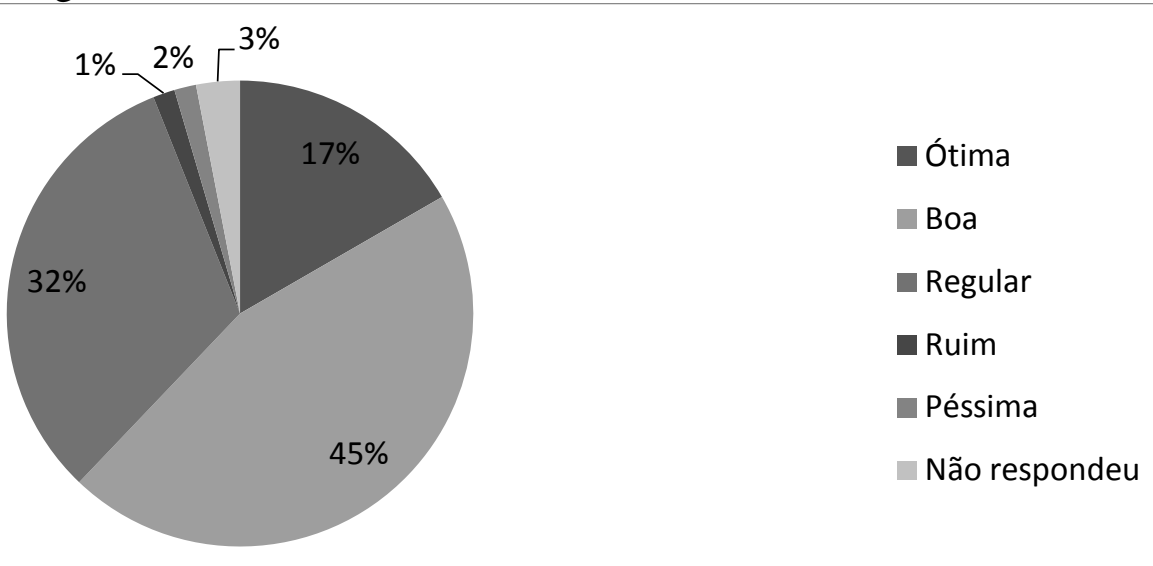

Fonte: Sá et al., 2018.

Por acreditarem que a água que chega as suas residências seja de boa qualidade, metade dos moradores a consomem imediatamente, apenas 36\% filtram ou fervem essa água (Figura 5), essa situação se repete em relação ao consumo da água armazenada, já que 56\% da população utilizam a água diretamente do local e apenas 32\% filtram ou fervem (Figura 6), isso pode trazer graves prejuízos à saúde pública do bairro, pois as chances de se consumir água contaminada se torna relevante.

No que se refere à qualidade da água, variados fatores podem levar a sua contaminação, acarretando a transmissão de substâncias ou microrganismos nocivos à saúde humana. Nesta perspectiva, destacam-se os poluentes orgânicos biodegradáveis, os orgânicos recalcitrantes ou refratários, os metais, os nutrientes em excesso provocados por escoamento de resíduos agrícolas e domésticos, a drenagem ácida da mineração, as espécies invasoras e as barragens e desvios (BRAGA et al., 2005).

Apesar da maioria dos moradores utilizarem a água diretamente da torneira e do local de armazenamento, $82 \%$ reconhecem que há presença de doenças infecciosas devido ao uso de água inadequada ao consumo. Dentre estas, foram citadas a diarreia (38\%) e a dengue (13\%), porém $12 \%$ dos entrevistados não souberam ou não responderam a essa questão (Figura 7), o que demonstra que o acesso às informações relacionadas à saúde pública ainda são deficientes. 


\begin{tabular}{|c|c|c|}
\hline & $\begin{array}{c}\text { GEOAMBIENTE ON-LINE } \\
\text { Revista Eletrônica do Curso de Geografia - UFG/REJ } \\
\text { Graduação e Pós-Graduação em Geografia } \\
\text { htpp://www.revistas.ufg.br/geoambiente } \\
\text { Jataí-Go | n 34 | Maio-Agos/2019 }\end{array}$ & $\begin{array}{c}\text { GEO } \\
\text { GF }\end{array}$ \\
\hline
\end{tabular}

Figura 5 - Forma de consumo da água encanada pelos moradores do bairro Santa Margarida, Salgueiro - PE.

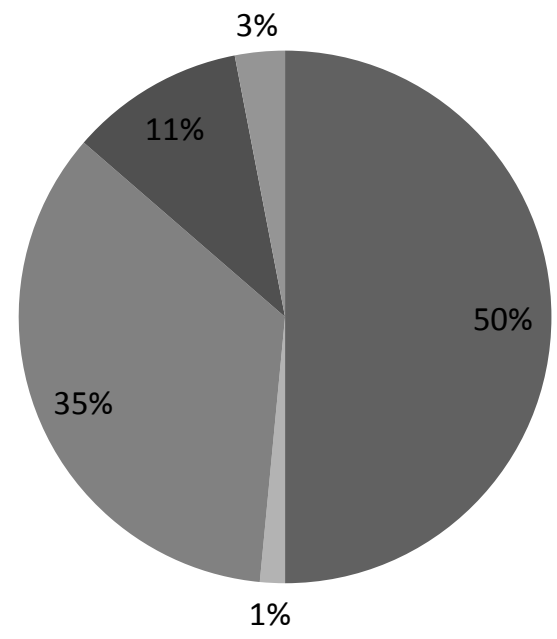

No estado que chega

Fervida

Filtrada

A água é comprada

Não respondeu

Fonte: Sá et al., 2018.

Figura 6 - Forma de consumo da água armazenada pelos moradores do bairro Santa Margarida, Salgueiro - PE.

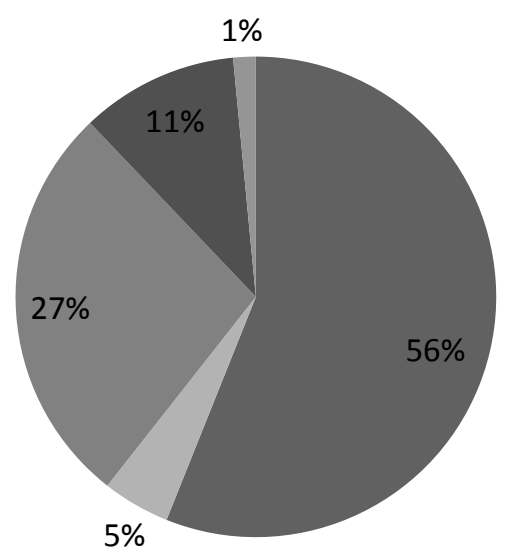

$$
\begin{aligned}
& \text { Direto do local de } \\
& \text { armazenamento } \\
& \text { Fervida } \\
& \text { Filtrada } \\
& \text { A água é comprada } \\
& \text { Não respondeu }
\end{aligned}
$$

Fonte: Sá et al., 2018. 


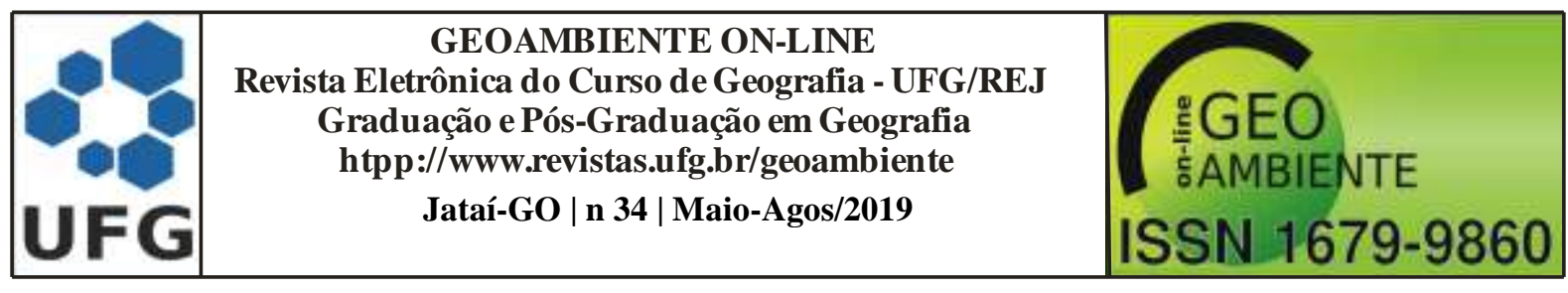

Figura 7 - Doenças relacionadas à ingestão de água contaminada, identificadas pelos moradores do bairro Santa Margarida, Salgueiro - PE.
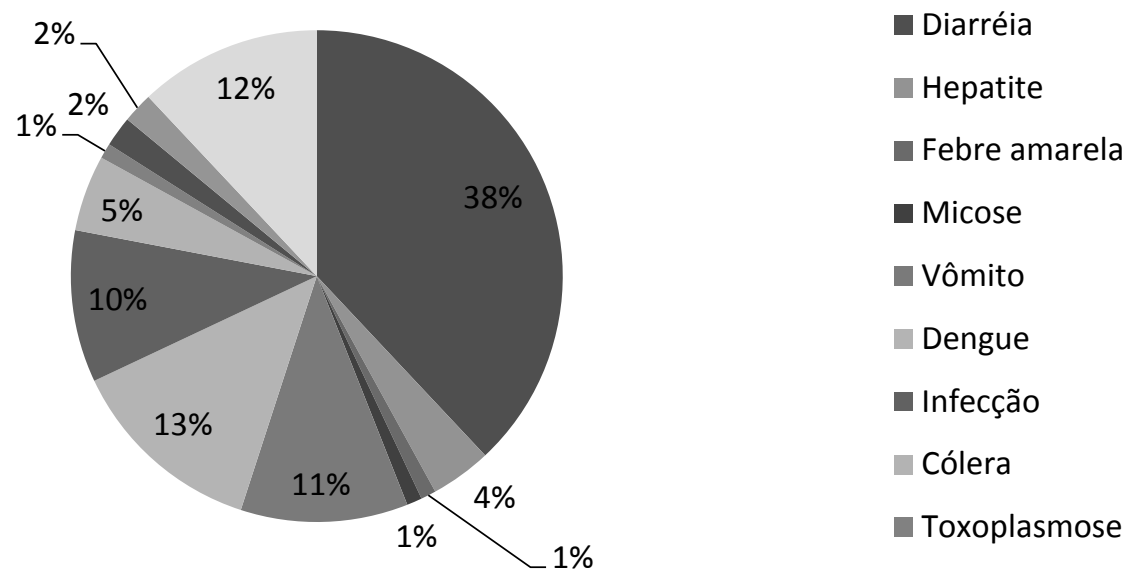

Fonte: Sá et al., 2018.

Para Silva, Heller e Carneiro (2012) há uma necessidade eminente de que se aborde em programas educativos, o tratamento domiciliar da água, não só para quem se utiliza de cisternas, mas para todos que fazem uso de fontes alternativas de abastecimento.

Durante a preparação dos alimentos, $42 \%$ apenas os lavam com a água que sai diretamente da torneira, 20\% usam cloro e 17\% acrescentam vinagre (Figura 8), o que demonstra que a preocupação com os alimentos consumidos, principalmente crus, ainda não é a prioridade entre os moradores do bairro.

Ainda que nesses locais a melhora dos tratamentos e depuração das águas residuais tenha reduzido a transmissão de grande parte dos patógenos bacterianos, existem várias rotas de exposição e contaminação por vírus entéricos, que podem ser adquiridos principalmente após o consumo de água ou de alimentos contaminados, incluindo os bivalves de ambientes marinhos contaminados, além de frutas e verduras irrigadas com água de baixa qualidade (WEI et al., 2011). 


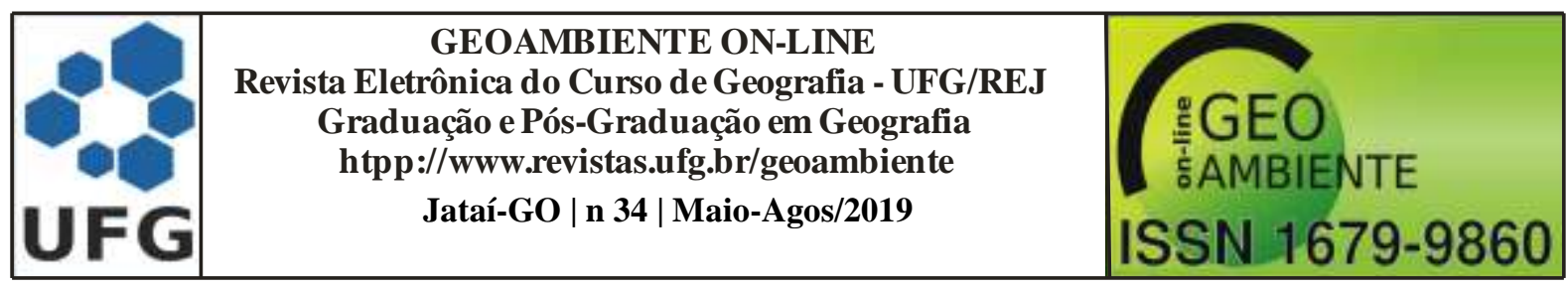

Figura 8 - Higienização dos alimentos consumidos pelos moradores do bairro Santa Margarida, Salgueiro - PE.

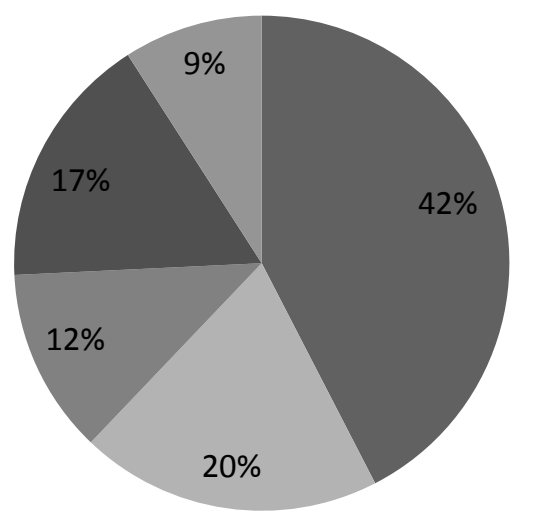

- Utiliza a água como sai da torneira

Usa cloro

- Usa água fervida

- Acrescenta vinagre

Não respondeu

Fonte: Sá et al., 2018.

3.2 Dados da vigilância epidemiológica do município.

Alguns trabalhos de educação sanitária e ambiental têm sido realizados na cidade, além disso, o esgotamento sanitário adequado em 62,8\% dos domicílios (IBGE, 2016), tem diminuído os casos de doenças relacionadas a veiculação hídrica, nos últimos anos, com exceção da diarreia, conforme apresentado na tabela 1 .

Assim, como as identificadas pelos moradores do bairro, a diarreia e as epidemias da dengue são as mais comuns em todo o município, sendo que a primeira houve um aumento de $57 \%$ entre os anos de 2015-2016 e queda de $12 \%$ entre 2016-2017, enquanto que a segunda caiu 35\% em 2016 em relação a 2015 e 79\% em 2017, mostrando que as campanhas educativas realizadas no município têm apresentado resultados positivos. Vale ressaltar também que nos últimos três anos não foram identificados casos de cólera, esquistossomose e leptospirose no município de Salgueiro - PE.

Em relação ao Bairro Santa Margarida foram identificados 365 casos de diarreia em 2015 (15\% do total de casos do município), 631 em 2016 (17\% do total de casos do município) e 449 em 2017 (15\% do total de casos do município), um dado expressivo, comparado ao tamanho do bairro. Em relação as epidemias da dengue este apresentou 25 casos em 2015 (8\%), 24 em 2016 (13\%) e apenas 1 caso em 2017 (3\%), porém esse último 


\begin{tabular}{|c|c|c|}
\hline & $\begin{array}{c}\text { GEOAMBIENTE ON-LINE } \\
\text { Revista Eletrônica do Curso de Geografia - UFG/REJ } \\
\text { Graduação e Pós-Graduação em Geografia } \\
\text { htpp://www.revistas.ufg.br/geoambiente } \\
\text { Jataí-Go | n 34 | Maio-Agos/2019 }\end{array}$ & $\begin{array}{c}\text { GEO } \\
\text { GF }\end{array}$ \\
\hline
\end{tabular}

dado não foi considerado consistente pela própria secretaria de saúde, já que os casos informados a mesma, foram relatados pelo Hospital Regional do Município e nem todos foram confirmados por exames clínicos (Tabela 1).

O maior desafio do setor Saúde, sobretudo da vigilância em saúde, é implementar as soluções para os problemas identificados nos diferentes níveis (locais, regionais), e desenvolver as ações de prevenção contra esses malefícios, bem como interagir com os setores afins para o desenvolvimento da infraestrutura, a execução das políticas e a conservação dos recursos naturais, como a água (BRASIL, 2015).

Tabela 1 - Doenças de veiculação hídrica no município de Salgueiro - PE.

\begin{tabular}{ccccccc}
\hline & \multicolumn{2}{c}{$\mathbf{2 0 1 5}$} & \multicolumn{2}{c}{$\mathbf{2 0 1 6}$} & \multicolumn{2}{c}{$\mathbf{2 0 1 7}$} \\
\cline { 2 - 7 } Doenças & Salgueiro & $\begin{array}{c}\text { Santa } \\
\text { Margarida }\end{array}$ & Salgueiro & $\begin{array}{c}\text { Santa } \\
\text { Margarida }\end{array}$ & Salgueiro & $\begin{array}{c}\text { Santa } \\
\text { Margarida }\end{array}$ \\
\hline Epidemias da & & & & & & \\
Dengue & 284 & 25 & 184 & 24 & 38 & 1 \\
Diarreia & 2388 & 365 & 3743 & 631 & 3277 & 449 \\
Hepatite A & 3 & 0 & 3 & 0 & 4 & 0 \\
Leishimaniose & 7 & 0 & 10 & 0 & 13 & 5 \\
\hline
\end{tabular}

Fonte: Sá et al., 2018.

\section{Conclusões}

- Os dados apresentados mostram que uma das maiores preocupações da população local é a interrupção da distribuição de água potável encanada, o que ocasiona o seu armazenamento, muitas vezes inadequado, potencializando as implicações epidemiológicas, como no aumento da incidência de doenças de veiculação hídrica e na prevalência de doenças crônicas, que acometem principalmente crianças e idosos. Acredita-se que os casos de epidemias da dengue, relevantes não só no bairro como no município, estão diretamente relacionados à armazenagem inadequada dessa água, já que os recipientes muitas vezes utilizados não são tampados corretamente, favorecendo a proliferação do mosquito Aedes aegypti, principal transmissor dessas doenças.

- Diante dos resultados coletados fica evidente a necessidade de políticas públicas que possam garantir à população o direito de acesso total ao saneamento básico adequado, 


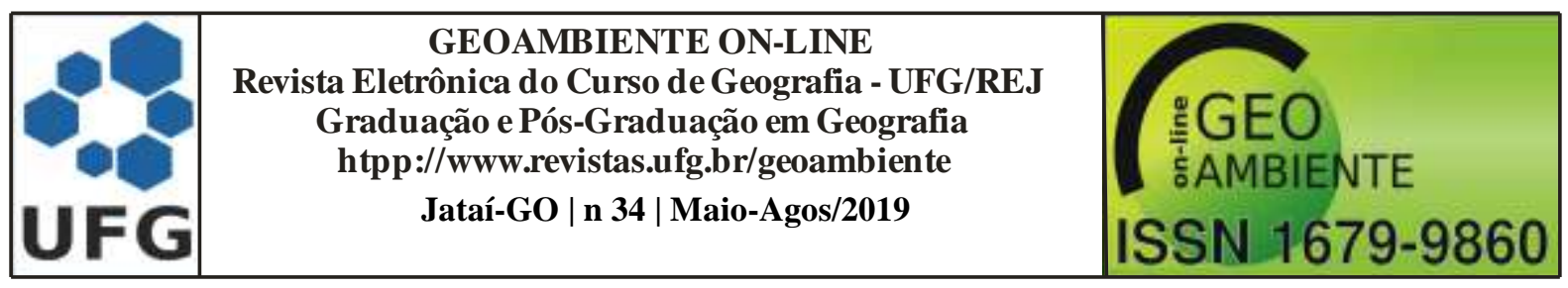

de forma que avalize a qualidade da água que chegará às residências. Além disso, é necessário que se invista ainda mais em campanhas educativas e preventivas, uma vez que ficou comprovado que há um número expressivo de pessoas que ignoram os riscos de ingerir água de má qualidade e alimentos sem os devidos cuidados de higienização adequada, pois quando se desconhece os riscos, não há cuidados necessários a fim de evitar as enfermidades. Dentre as enfermidades que mais acometem a população pesquisada encontra-se a diarreia, doença que tem como sua principal fonte de transmissão a água ou alimentos contaminados pela bactéria da família Shigella.

- Assim, a efetivação de políticas públicas e o estímulo de campanhas educativas e preventivas possibilitarão o alcance de melhores condições de governabilidade, permitido que o Estado interaja com a sociedade, no desenvolvimento de ações conjuntas e eficazes nos setores de desenvolvimento urbano, habitacional, saneamento e saúde, visando à promoção da saúde pública local e o enfrentamento da complexidade de fatores que evidenciam sua vulnerabilidade.

\section{Referências}

AMARAL, L. A. et al. Água de consumo humano como fator de risco a saúde em propriedades rurais. Rev. Saúde Pública, v.37, n.4, p.10-514, 2003.

BRAGA, B; HESPANHOL, I.; CONEJO, J. G. L.; MIERZWA, J. C.; BARROS, M. T. L.; SPENCER, M.; PORTO, M.; NUCCI, N.; JULIANO, N.; EIGER, S. Poluição Ambiental: O meio aquático. In: (Org.). Introdução a Engenharia Ambiental. Parte II. 2 ed. São Paulo: Pearson Prentice Hall, 2005. p. 75-124.

BRANCO, S. M.; AZEVEDO, S. M. F. O.; TUNDISI, J. G. Água e Saúde Humana. In: REBOUÇAS, A. da C.; BRAGA, B.; TUNDISI, J. G. (Org.). Águas doces do Brasil: capital ecológico, uso e conservação. 3 ed. São Paulo: Escrituras, 2006. p. 246-247.

BRASIL. Ministério da Saúde. Secretaria de Vigilância em Saúde. Doenças infecciosas e parasitárias: guia de bolso. Ed 5. Brasília: Ministério da Saúde, 2005. 320p. Disponível em <http://bvsms.saude.gov.br/bvs/publicacoes/guia_bolso_5ed2.pdf >. Acesso em 15 de janeiro de 2018. 


\begin{tabular}{|c|c|c|}
\hline & $\begin{array}{c}\text { GEOAMBIENTE ON-LINE } \\
\text { Revista Eletrônica do Curso de Geografia - UFG/REJ } \\
\text { Graduação e Pós-Graduação em Geografia } \\
\text { htpp://www.revistas.ufg.br/geoambiente } \\
\text { Jataí-GO | n 34 | Maio-Agos/2019 }\end{array}$ & $\begin{array}{c}\text { GEO } \\
\text { G G }\end{array}$ \\
\hline
\end{tabular}

. Departamento de Vigilância em Saúde Ambiental e Saúde do Trabalhador. Análise de indicadores relacionados à água para consumo humano e doenças de veiculação hídrica no Brasil, ano 2013: utilizando a metodologia da matriz de indicadores da Organização Mundial da Saúde / Ministério da Saúde, Secretaria de Vigilância em Saúde, Departamento de Vigilância em Saúde Ambiental e Saúde do Trabalhador. Brasília: Ministério da Saúde, 2015. - Ministério do Meio Ambiente. Água: um recurso cada vez mais ameaçado. Disponível em <http://www.mma.gov.br/estruturas/sedr_proecotur/_publicacao/140_publicacao0906200902 5910.pdf>. Acesso em 19 de janeiro de 2018.

INSTITUTO BRASILEIRO DE GEOGRAFIA E ESTATÍSTICA. IBGE Cidades. 2016. Disponível em <https://cidades.ibge.gov.br/brasil/pe/salgueiro/panorama>. Acesso em 27 de dezembro de 2017.

JUNQUEIRA, R. D. Geografia Médica ou da Saúde. Rev. Brasileira de Geografia Médica e da Saúde. v. 5, n.1, p.1-10, 2009.

MARQUES, G. R. A .M. M.; CHAVES, L. S. M.; SERPA, L. L. N.; ARDUÍNO, M. DE B.; CHAVES, F. J. M. Água de abastecimento público de consumo humano e oviposição de Aedes aegypti. Rev. de Saúde Pública, v.47, n.3, p.579-587, 2013.

NERE, J. J. M. Uso de geotecnologia para a comparação entre Índice de Doenças de Veiculação Hídrica e Índice de Condição Material de Vida na área urbana de Salinas MG. 2010. 82f. Dissertação (Mestrado em Desenvolvimento Regional e Meio Ambiente) Universidade Estadual de Santa Cruz, Ilhéus, 2010.

OLIVEIRA, L. M. de; CHIEREGATO, R.; PEREZ JUNIOR, J. H.; GOMES, M. B. Manual de contabilidade tributária. São Paulo: Atlas, 2004. 573 p.

RAZZOLINI, M. T. P.; GÜNTHER, W. M. R. Impactos na Saúde das Deficiências de Acesso a Água. Rev. Saúde Soc. São Paulo, v.17, n.1, p.21-32, 2008.

ROUQUAYROL, M. Z.; SIVA, M. G. C. Epidemiologia \& Saúde. 7 ed. Rio de Janeiro: MedBook. 2013. 736 p. 


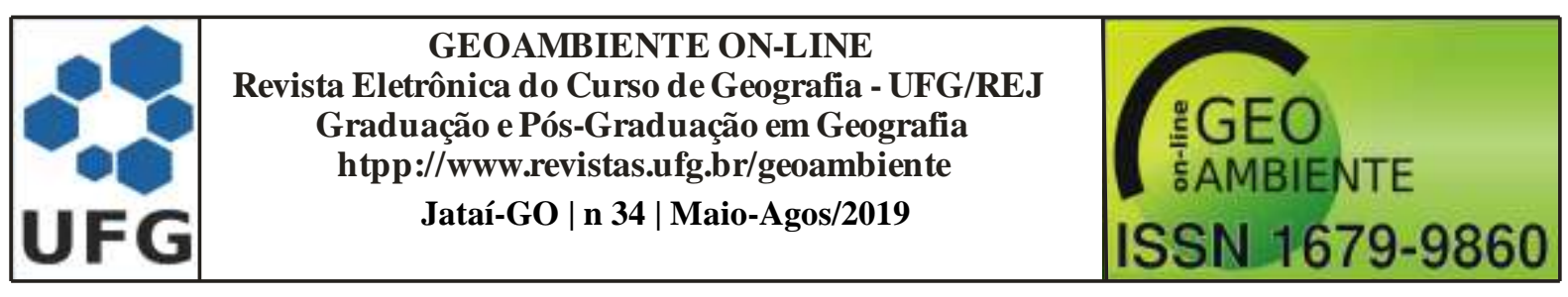

SALGUEIRO. Salgueiro em números. 2017. Disponível em <http://www.salgueiro.pe.gov.br/munic_numeros.htm>. Acesso em 24 de abril de 2019.

SILVA, C. V. da; HELLER, L.; CARNEIRO, M. Cisternas para armazenamento de água de chuva e efeito na diarreia infantil: um estudo na área rural do semiárido de Minas Gerais. Rev. Engenharia Sanitária Ambiental, v.17, n.4, p.393-400, 2012.

SILVA FILHO, A. C.; MORAIS, R. D. de; SILVA, J. B. da. Doenças de veiculação hídrica: dados epidemiológicos, condições de abastecimento e armazenamento da água em massaranduba/PB. Rev. Geoambiente online, n. 20, 2013. Disponível em <www2.jatai.ufg.br/ojs/índex.php/geoambiente>. Acesso em 15 de fevereiro de 2018.

WEI, J. et al. Internalization of Murine Norovirus 1 by Lactuca Sativa During Irrigation. Rev. Applied and Environmental Microbiology, v.77, n.7, p. 508-512, 2011. 